\title{
Carta a Gonçalves Dias (sobre o poema A minha musa)
}

\section{Juva Batella}

\author{
Caro Gonçalves,
}

Li seu poema $A$ minha musa e, inspirado, agora lhe escrevo, para lhe dar alguma satisfação. Vou chamar-lhe você apenas para adequar o tratamento ao costume de meus dias e ao local de onde falo. Estivesse eu no exílio à época em que você por lá andou e estaríamos agora a tratar-nos por tu ou mesmo vós - provavelmente aos prantos, saudosos, apaixonados e poetas. Peço-lhe que não se incomode com o óbvio de minhas palavras, mas tenho a dizer-lhe que o tempo passou e você se tornou não apenas representante de um movimento e uma época chamados romantismo, como também nome de rua, a rua Gonçalves Dias, no centro da cidade do Rio de Janeiro. Seu trabalho constitui objeto de estudo e é este o meu trabalho de hoje. Perdoe, pois, as ululâncias. Por outro lado, creio que você aprenderá bastante sobre si mesmo com o conhecimento que se formou após sua breve estada de 41 anos sobre o planeta, terminada estupidamente, acredito, apesar de todo o romantismo envolvido no mero fato de morrer naufragado, que para um romântico não deve ser pouca coisa - melhor que dormindo ou qualquer outro passamento inglório. Vamos, então, caro Gonçalves, trabalhar.

Seu poema é parte de um grupo de poemas com o nome de "Primeiros Cantos". As razões para o título repousam em seu desejo de que tais cantos sejam o início de uma série. "Dei o nome de 'Primeiros Cantos' às poesias que agora publico, porque espero que não serão as últimas”, escreveu você em seu prefácio, imbuído, acredito, da mais sincera superstição. O poema é composto de vinte estrofes não propriamente uniformes, uma vez que você optou por menosprezar "regras de mera convenção" e utilizou os ritmos da metrificação portuguesa apenas quando estes se mostraram úteis àquilo que pretendia expressar. As vinte estrofes ficam divididas em três tipos: as quatro primeiras, quadras ou quartetos; as dez seguintes, quintilhas ou quintetos, com a décima se ligando à primeira das seis seguintes, novamente quadras; e a última, que não passa de uma sextilha. "Que importância há nisto?”, perguntará você, e eu não saberia responder 
senão alegando a necessidade de reconhecer a importância e o lugar que tudo tem, inclusive estes detalhes versificatórios - em outras palavras, eu não saberia responder, senão com perguntas. Por que razão escolheu você estas formas e não outras? Por que rimar alguns versos, e não outros? A falta de uniformidade já anunciada em seu prefácio chegará ao paroxismo menos de cem anos depois. Falo do modernismo, mas isto é outra história, e eu não saberia por onde começar a contá-la — provavelmente começaria por você, com quem aqui continuo. Dê-me, pois, a mão, e vamos trabalhar.

Estas poesias "não têm unidade de pensamento entre si, porque foram compostas em épocas diversas — debaixo de céu diverso — e sob a influência de impressões momentâneas". Chego mesmo a imaginá-lo ao pé do Douro ou do Tejo, com lágrimas nos olhos, a mirar o céu e inflar-se de inspiração - esta ração estranha e indefinível que superalimentou incontáveis gerações de poetas da sua linhagem, caracterizando sobremaneira o seu método de trabalho, ou o seu "deixar-se arrebatar". Posso mesmo imaginá-lo do mesmo modo como imaginei a musa que você tão bem descreveu neste seu poema que agora estudo: desejosa de solidão, amante do silêncio dos prados floridos e da selva umbrosa - palavras suas, sexta estrofe, versos um e dois. Posso arriscar também - e é desnecessário dizer que estou a interpretar - que o retrato de sua musa em muitos momentos se confundiu com uma imagem que tenho sua e de seu modo de trabalhar. Sua musa é sua inspiração, que não deixa de ser o seu "eu lírico", para ficarmos assim mais bonitos. Você escreveu: "Com a vida isolada que vivo, gosto de afastar os olhos de sobre a nossa arena política para ler em minha alma...". Sua musa circula afastada do burburinho dos banquetes e dos alpendres dos senhores, e está atenta ao "sussurro das águas, os acentos / de profundo sentir".

Minha musa não é como ninfa

Que se eleva das águas - gentil -

Co’um sorriso nos lábios mimosos

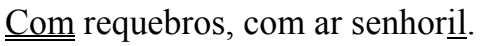

Nesta estrofe, assim como nas quatro seguintes, você vai traçar o retrato em negativo de sua musa, cantando o que ela não é e atirando para longe aquela familiar imagem da antigüidade clássica que nos veio de Homero: as Musas habitantes dos palácios e enturmadíssimas com os deuses e os vates. Estou falando daquele grupinho de nove, as nove divindades, filhas de Zeus, que presidiam às atividades desinteressadas do espírito - faladeiras, badaladoras e mais vivas, bem mais vivas que a sua, que não é 
como a ninfa. A ninfa - estou parecendo um dicionário - era a divindade fabulosa dos rios, montes e bosques, e você a caracteriza sensualmente, referindo os lábios, o sorriso e os quadris, representados pelos requebros. Requebro pode ser qualquer gesto, você dirá. Modernamente, porém, caro Gonçalves, o requebro se dá mais para baixo, em regiões glúteas. Não vá me convencer de que não foi essa a sua intenção, ainda mais se levarmos em conta que a própria palavra ninfa carrega às costas sentidos outros, oriundos da disciplina da anatomia e utilizados na designação dos pequenos lábios da vulva, ou boceta, que significa caixinha redonda, oval ou oblonga, ou ainda uma determinada variedade da tangerineira, veja só. A rima desta quadra, assim como das três seguintes, está no segundo e no quarto versos. Os dois últimos iniciam-se da mesma maneira, contribuindo assim para uma leitura mais rítmica, enfática e levemente redundante. No último verso acontece o fenômeno da cesura, que divide a leitura em duas partes: "Com requebros, com ar senhoril", chamando a atenção do leitor para os requebros, ou seja, os gestos, ou seja, os quadris.

\footnotetext{
Nem lhe pousa nas faces redondas Dos fagueiros anelos a cor; Nesta terra não tem uma esp'rança, Nesta terra não tem um amor.
}

Estou começando a convencer-me, Gonçalves, da morbidez deste poema. Ainda não havia falado neste assunto com receio de me estar precipitando, mas a morte ronda estes versos, se não é ela a protagonista deste retrato em branco e preto. Sua musa é branca como é branca a morte, e não lhe pousa nas faces redondas a cor. Esta estrofe diz do que não acontece à sua musa: não lhe acontece o rubor. A terra de que você fala nos dois últimos versos é uma terra desolada. Isto um dia vai ser o título de um belo poema — ou melhor, já foi. Os dois últimos versos começam iguais, e seguem iguais até quase o final, com a incorporação da primeira letra de "amor", casando assim "uma esp'rança" e "um amor". A repetição produz um efeito obsedante que fortalece a desolação desta sua terra. Há nos dois primeiros versos um cavalgamento, ou seja, "processo poético de pôr no verso seguinte uma ou mais palavras que completam o sentido do verso anterior”, segundo palavras dicionárias. Refiro-me à cor dos anelos fagueiros a pousar, ou melhor, a não pousar, nas faces redondas de sua musa. A palavra usada para completar o sentido que permaneceu aberto no primeiro verso é chamada de parte excedente. Neste caso, o excedente é a palavra “cor". Estas informações eu tirei de um 
livrinho muito bom que depois the passo, chamado Versificação portuguesa, de um sujeito chamado Manuel Said Ali, que morreu em 1953 e, portanto, você já deve conhecer.

Como fada de meigos encantos, Não habita um palácio encantado, Quer em meio de matas sombrias, $\underline{\text { Quer à beira do mar levantado. }}$

Uma bela imagem, embora já gasta aqui neste tempo de onde falo: a imagem do castelo ao pé de uma escarpa, socado por ondas gigantes, ou então escondido na mata. Isto se tornou imagem recorrente de desenhos para crianças, lugar comum do terror em cores. Os dois últimos versos abrigam idéias de altitude e profundidade, vida e morte. Estamos a falar disso, e a morte é ambas as coisas - seu estado de matéria putrefata no subsolo e seu estado de espírito sorridente nas alturas - , materialismo e metafísica. Até mesmo a filosofia, quando não sabe o que fazer com este velho dilema, pode dar-se ao luxo de ser romântica, como nós ainda o somos, profundamente. No interior da mata sombria e à beira do mar levantado são imagens femininas e masculinas. Esta estrofe diz do lugar onde sua musa não habita. Novamente a repetição do início nos dois últimos versos, agora menor, porém igualmente enumerativa, em "Quer", seguido, nas duas linhas, de uma idéia de lugar: "em meio de" e "à beira do". Há uma certa redundância em "meigos encantos" e "palácio encantado" — é muito encanto para tão pouco espaço. Do mesmo modo como falei redundância, poderia, se fosse minha intenção o elogio, falar aliteração. Interpretações, intenções, gostos e algum rigor assim caminha a crítica. Trata-se, por outro lado, de uma das estrofes mais ritmadas. $\mathrm{O}$ "m" de "meigos" se encontra praticamente na mesma posição do "m" de "matas" (ao que se segue o "m" de "em meio") e de "mar". Mais aliterações.

Não tem ela uma senda florida, De perfumes, de flores bem cheia, Onde vague com passos incertos, $\underline{\underline{\text { Quando }}}$ o céu de luzeiros se arreia.

O último verso é o único responsável por ser esta uma bela estrofe. Luzeiro, no singular, tem um sentido mais literal que sua versão plural, que significa olhos. Luzeiro é tudo aquilo que emite luz, mas luzeiros são olhos no sentido poético - olhos que por si não emitem luz alguma, embora a reflitam, e aqui o verso ganha mais sentidos: 
podemos imaginar os olhos de sua musa, olhos que refletem a luz que vem dos olhos do céu quando o céu se arreia, ou seja, se enfeita. Esta estrofe fala daquilo que sua musa não tem: uma senda florida, cheia de perfumes e de flores. Há no segundo verso uma cesura: "De perfumes, de flores bem cheia". Os dois últimos versos não comportam inícios iguais, como as estrofes anteriores, mas mesmo assim conseguem o efeito de ênfase e repetição, já que começam com os advérbios "onde" e "quando".

\author{
Não é como a de Horácio a minha Musa; \\ Nos soberbos alpendres dos Senhores \\ Não é que ela reside; \\ Ao banquete do grande em lauta mesa, \\ Onde gira o falerno em taças d'oiro, \\ Não é que ela preside.
}

Esta é a última estrofe em que se diz o que sua musa não é — neste caso, o que não faz: não reside nos alpendres dos senhores e não preside aos banquetes. Há aqui uma homenagem ao seu poeta latino predileto, não apenas graças à menção direta ao velho Horácio, mas também à sua bebida preferida — o falerno, cujo nome vem de uma região da Itália também chamada Falerno. "É notório como Horácio bebia falerno", já escreveu Ramalho Ortigão, espalhando, indiscreto, a notícia. Trata-se de uma sextilha que segue o esquema nna nna, onde " $n$ " representa a linha não-rimante, e "a" a rima nos versos três e seis. Eu não vou mais falar de rimas. Estou um chato.

Ela ama a solidão, ama o silêncio.

Ama o prado florido, a selva umbrosa

E da rola o carpir.

Ela ama a viração da tarde amena,

O sussurro das águas, os acentos

De profundo sentir.

Sua musa é pouco festeira, como você já havia indicado na estrofe anterior, e gosta de estar próxima aos elementos naturais. Quando digo "sua musa", estou, de fato, me referindo a você, caro Gonçalves; a você e ao seu "eu lírico", para usar e abusar mais uma vez deste terno termo. Sua musa é a musa do poeta, entenda-se, e o poeta é você, você mesmo, que morreu afogado, não em lágrimas, mas no mar salgado. Rimei. Temos aqui um quadro da Mãe Natureza, semelhante àquilo que você fez nas estrofes três e quatro. Repare na repetição da idéia entre: "Quer em meio de matas sombrias" ( $3^{\mathrm{a}}$ estrofe) e "a selva umbrosa" ( $6^{\text {a }}$ estrofe); "Não tem ela uma senda florida, / De 
perfumes, de flores bem cheia" ( $4^{\mathrm{a}}$ estrofe) e "Ama o prado florido" ( $6^{\mathrm{a}}$ estrofe). Tudo isto para dizer que está claro o desejo de sua musa por aquilo que ela não pode, ou não deve, possuir. Ela não tem uma senda florida cheia de perfumes e de flores e, no entanto, ama o prado florido, a selva úmida e escura e os lamentos da rolinha. Mas nem tudo são flores. Sua musa é melancólica e seu comportamento coincide com o dos novos poetas, chamemo-los assim, em oposição aos velhos poetas da antigüidade, representantes das tradições de sua sociedade - o vate, o que faz vaticínios; e o aedo, o que canta a história.

\footnotetext{
D'Anacreonte o gênio prazenteiro, Que, de flores cingia a fronte calva Em brilhante festim, Tomando inspirações à doce amada, Que leda lh'enflorava a ebúrnea lira; De que me serve a mim?
}

Aparece, enfim, a primeira pessoa deste poema. O possessivo "minha musa" funciona certamente como um indicativo da primeira pessoa, mas direcionado a uma terceira, a quem descreve. Temos desta vez uma pergunta, e uma pergunta típica do subjetivismo que agora quer manifestar-se. "De que me serve a mim?", pergunta o último verso. $\mathrm{O}$ mundo só serve se serve a mim; só vale a pena se vale para mim. Caso contrário, morra o mundo ou morrerei eu, o que pode dar no mesmo - e dará. Vocês, românticos, são o oito e o oito mil. Os elementos desta estrofe sugerem festa: o poeta grego Anacreonte, o prazer de seu gênio, as flores sobre sua careca, o bate-coxa, sua lira de marfim, a doce amada inspiradora - tudo isso, para que serve, se para mim, no caso você, não serve? Vocês dois são poetas, quem haverá de negar?, mas de gênios diversos. O que é bom para Anacreonte não será bom para Gonçalves.

Canções que a turba nutre, inspira, exalta

Nas cordas magoadas me não pousam

Da lira de marfim.

Correm meus dias, lacrimosos, tristes, Como a noite que estende as negras asas

Por céu negro e sem fim.

Não pousam em mim, vindas das cordas magoadas da lira de marfim, as canções que a turba nutre, inspira e exalta, dizem seus versos, agora desenrolados destas esdrúxulas inversões. Turba, neste caso, pode seguir seu terceiro significado: vozes que 
cantam em coro. Os primeiros três versos desta estrofe, temo que não ficaram bem, tamanha foi a ginástica inversionista que você utilizou. Não chega a ser uma sínquise, que é uma inversão exagerada dos termos da frase - aprendi com o professor Manuel —, mas, convenhamos, estes não são seus melhores versos... E já que estamos a falar em melhores versos, permita-me um parêntese que vai deleitá-lo. O "Hino nacional" você não conhece, embora, sem o saber, o tenha inspirado. O autor, o sr. Osório Duque Estrada, venceu em 1909 o concurso para a escolha da letra, e há um verso que foi chupado da sua "Canção do exílio" (se não foram esses os seus melhores versos, de certo figuram como os mais conhecidos). "Nosso céu tem mais estrelas, / Nossas várzeas têm mais flores, / Nossas flores têm mais vida, / Nossa vida mais amores.” E agora o hino do Osório: "Teus risonhos, lindos / campos, têm mais flores; / Nossos bosques têm mais vida, / Nossa vida no teu seio, / mais amores". Fecham-se os parênteses. Onde estávamos? Afora o possessivo "minha", do título do poema, que é também o início, e a pergunta que termina a estrofe anterior, você não voltou a mostrarse até chegarmos a esta estrofe. Até então, apenas a sua musa e o que ela não era ou não fazia. Agora está o lamuriante poeta a falar de seus dias lacrimosos e tristes — seus dias, que são como as noites, assim como a vida, esta vida, será como a morte.

\footnotetext{
É triste a minha Musa, como é triste

O sincero verter d'amargo pranto D'órfã singela;

É triste como o som que a brisa espalha, Que cicia nas folhas do arvoredo Por noite bela.
}

Sim, sua musa é órfã, já que não é filha de uma tradição de musas que sabemos serem diferentes da sua. Musas que andam juntas, em bandos de nove, ao contrário da sua, que, sozinha, erra pelos campos... E as recorrências à natureza prosseguem; a natureza serve para o que se quiser; está à mão do poeta, porque a terra é boa e em plantando nela tudo dá. Pode ser a tristeza ou a alegria, bastando para a idéia de melancolia escurecer os campos e ressecar as árvores, ou, em caso oposto, colorir as pétalas das flores e azulejar o céu. A noite da estrofe anterior tinha asas negras e seu céu era negro e sem fim; a noite desta estrofe é apenas bela, e sua tristeza, serena. Sua musa, mais uma vez, vai chorar de braços dados com a natureza, porque seu choro será como o som da brisa chacoalhando as árvores. E se sua alma, Gonçalves, está negra e sombria é porque a noite certamente não é de lua. 
É triste como o som que o sino ao longe

Vai perder na extensão d'ameno prado

Da tarde ao cair,

Quando nasce o silêncio envolto em trevas,

Quando os astros derramam sobre a terra

Merencório luzir.

$\mathrm{Na}$ estrofe anterior a palavra triste surge três vezes, reforçando o espelhamento entre a tristeza da musa, a do poeta e a da própria natureza. "É Triste como" e "como é triste" são as expressões utilizadas. Esta estrofe de agora é a continuação das analogias, e o som da tristeza soa como o de um sino se perdendo ao longo e ao longe de um campo aberto num cair de tarde. Gostou? Mais melancolia, impossível. A aliteração entre "som", "sino" e "silêncio" fica registrada. O merencório luzir é a melancólica pouca luz do entardecer, o crepúsculo, o momento de pior luminosidade, a chamada "hora má".

\footnotetext{
Ela então, sem destino, erra por vales, Erra por altos montes, onde a enxada Fundo e fundo cavou; E pára; perto, jovial pastora Cantando passa - e ela cisma ainda Depois que esta passou.

Além — da choça humilde s'ergue o fumo Que em risonha espiral se eleva às nuvens Da noite entre os vapores; Muge solto o rebanho; e lento o passo, Cantando em voz sonora, porém baixa, Vêm andando os pastores.
}

Há aqui uma bela alusão crítica aos movimentos passados, no seu caso a poesia árcade. Representam estas duas estrofes a vida pastoral, e todo o poema é a constatação de um movimento de diferença entre um tipo de fazer poético e outro - a vida no campo, a natureza amiga e serena, a musa de Horácio, o próprio Horácio e seu famoso bordão fugere urbem (fugir da cidade). Agora damos com a pastora que passa, jovial, só faltando estar aos pulinhos, encharcada de serenidade bucólica. Passa cantando ao pé de sua musa, errática e cismenta. Como são diversas estas duas criaturas: uma, preocupada, desconfiada, solitária e triste; a outra, inteira unida ao campo, nunca sozinha, pois também unida à fauna caprina. $\mathrm{O}$ romantismo, aqui presente graças a esta sua musa diferente das outras, mostra-se como a possibilidade de auto-conhecimento através do 
cismamento de si. Se a musa erra sem destino, é porque está à procura de si mesma, em atitude radicalmente diversa do alheamento pastoril. O dia-a-dia no campo se encontra condensado na segunda estrofe. É o mesmo campo que os poetas árcades cantavam, porém nele não moravam, pois eram boêmios urbanóides flagrados em pleno fingimento poético. Tudo é tranqüilo e até a fumaça da chaminé da humilde casa chega ao cúmulo de ser risonha. Vem a tarde e vêm também, cantarolantes e famintos, os homens anunciados pelo mugir do rebanho. Tudo é alheamento. A natureza, para eles, é cenário; para você, um espelho d'alma tortuosa.

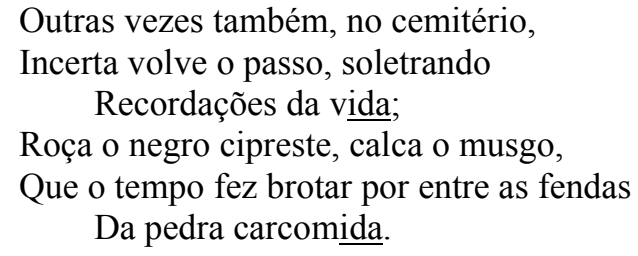

Sua musa continua seu passeio e agora dá no cemitério. Retornam mais nítidas as referências à morte. Ela não tem nada melhor para fazer, senão recordar a vida, que para ela é algo que já não mais é, mas foi, e é por isso que recorda. E suas recordações são como o musgo que, não obstante o tempo, e talvez graças a ele, brota por entre as fendas da pedra carcomida, regado a torrentes de lágrimas. São as fendas a memória; é a pedra o esquecimento e o correr do tempo. Há nesta estrofe dois tempos, o da vida, que é crescimento e musgo e também o negro cipreste; o da morte, que é pedra imóvel e fendida - o tempo fora do tempo.

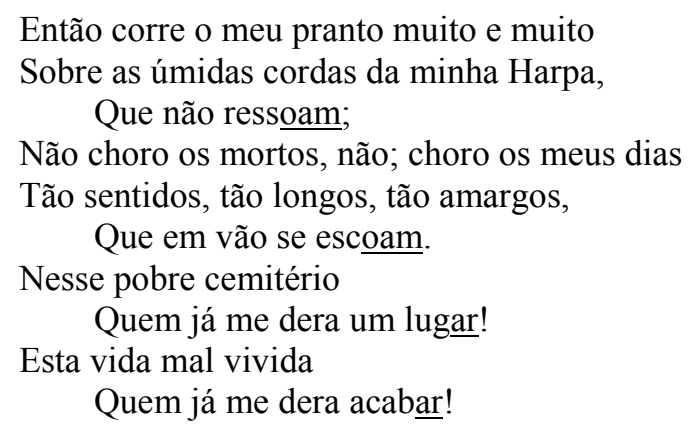

Volta o poeta a falar de si, volta o arrebatamento. Os elementos desta estrofe são uma harpa cujas cordas não ressoam, um pranto que jorra sem parar e uma insuportável autocomiseração. Não são os mortos, diz você, mas a morte que há em sua vida. Isto me lembra um poema e um poeta: “Toada de Portalegre”, do português José Régio. Veja-se 
este trecho: "O amor, a amizade e quantos sonhos de cristal sonhara, bens deste mundo que o mundo me levara, de tal maneira me tinham, ao fugir-me, deixado só, nulo, atônito, a mim, que tanto esperara ser fiel e forte e firme, que não era mais que morte a vida que então vivia, auto-cadáver!" (não pus as barrinhas para separar os versos porque estou aqui escrevendo de memória). A quadra que se segue à sextilha, e a ela ligada, não passa do bom e velho escapismo romântico. É uma quadra exclamativa, redundante e para mim sem grande valor.

\author{
Tenho inveja ao pegureiro, \\ Da pastora invejo a vida, \\ Invejo o sono dos mortos \\ Sob a laje carcomida. \\ Se qual pegão tormentoso, \\ O sopro da desventura \\ Vai bater potente à porta \\ De sumida sepultura: \\ Uma voz não the responde, \\ Não lhe responde um gemido, \\ Não lhe responde uma prece, \\ Um ai - do peito sentido. \\ Já não têm voz com que falem, \\ Já não têm que padecer; \\ No passar da vida à morte \\ Foi seu extremo sofrer. \\ Que lh'importa a desventura? \\ Ela passou, qual gemido \\ Da brisa em meio da mata \\ De verde alecrim florido.
}

Esta inveja é, de certo, irônica. Os alvos são o pegureiro e a pastora, ambos a viver de rebanhos, ambos alienados, como o são os mortos, alienados em seu interminável sono. Da pastora você invejará a vida, e dos mortos a morte. Somente sob estes papéis, você, poeta, estará a salvo de si mesmo e de seus cismamentos. Mais uma vez a laje carcomida é sua obsessão. É bom estar morto, pois já não será preciso responder ao sopro da desventura, que é forte como vento de tormenta e é potente quando bate à porta em busca de uma resposta. Mas se bate à porta de uma sepultura é a voz da sepultura que lhe responde, e a voz da sepultura não é gemido, não é prece e não é grito - que esta é a voz dos vivos. A voz da sepultura pode ser o vento. Aos vivos é que se dirigem estas estrofes, para mostrar-lhes que o sofrimento não é estar morto, mas 
morrer. "No passar da vida à morte / Foi seu extremo sofrer." E a desventura, se para os vivos é um pegão tormentoso que bate potente à porta das sepulturas, para os mortos não passa de gemido da brisa que passa pela mata verde.

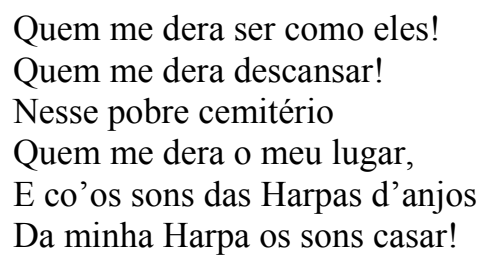

É chegada a hora do juízo final deste poema, a morte do poeta, a provável comunhão com a musa - comunhão que, em verdade, sempre existiu, não fossem vocês dois, você e sua musa, a mesma coisa. Chamo-o de coisa, não se aborreça, na falta de palavra melhor. Você, sendo sua musa, é sua própria inspiração e fonte de si mesmo. A reunião, no céu, da harpa do poeta com as outras harpas é o encontro poético por excelência. Não seria mau terminar também exclamativamente, e é por isso, caro Gonçalves, que eu assim termino, como você e sua turma terminariam, ambíguo, contraditório e em tormentoso dilema — inteiramente absurdo: que viva a morte!

Seu,

Juva 